\title{
Evaluation of $N$-Bromosuccinimide as a New Analytical Reagent for the Spectrophotometric Determination of Fluoroquinolone Antibiotics
}

\author{
Hassan Askal, ${ }^{a}$ Ibrahim RefaAt, ${ }^{a}$ Ibrahim Darwish, ${ }^{*, a, 1)}$ and Mostafa MarzouQ ${ }^{b}$ \\ ${ }^{a}$ Department of Pharmaceutical Analytical Chemistry, Faculty of Pharmacy, Assiut University; Assiut 71526, Egypt: and \\ ${ }^{b}$ Department of Pharmaceutical Analytical Chemistry, Faculty of Pharmacy, Al-Azhar University; Assiut, 71524, Egypt. \\ Received January 21, 2007; accepted August 12, 2007
}

\begin{abstract}
Analytical studies were carried out, for the first time, to evaluate the use of $N$-bromosuccinimide (NBS) as an analytical reagent for the spectrophotometric determination of eleven therapeutically important fluoroquinolone antibiotics (FQA). The procedures involved the reaction of the FQA with NBS and subsequent measurement of the excess NBS by its reaction with $p$-phenylenediamine (PDA) to give a violet colored product that was measured at $530 \mathrm{~nm}$. Different variables affecting the reaction (concentration of NBS, concentration of PDA, pH of reaction medium, reaction time, and the diluting solvents) were carefully studied and optimized. The molar ratio and mechanism of the reaction between each of the studied FQA with NBS were proposed using UV-vis, IR, and NMR techniques. Under the optimum reaction conditions, the analytical method was developed and validated. Beer's law was obeyed in the general concentration range of $3-25 \mu \mathrm{g} / \mathrm{ml}$. The assay limits of detection and quantitation were $0.33-1.29$ and $1.10-4.31 \mu \mathrm{g} / \mathrm{ml}$, respectively. The precision of the method was satisfactory; the values of relative standard deviations did not exceed $2 \%$. The proposed method was successfully applied to the analysis of the investigated FQA in their pure and pharmaceutical dosage forms without interference from the common excipients (label claim values were $99.85-100.17 \pm 0.13-0.59 \%$ ). Interference from ascorbic acid, that is co-formulated as a stabilizer for the ampoule form, was avoided by its pre-oxidation with potassium bromate before applying the analytical procedure. The results obtained by the proposed method were comparable with those obtained by the official and reported methods.
\end{abstract}

Key words fluoroquinolone antibiotic; $N$-bromosuccinimide; $p$-phenylenediamine; spectrophotometry; pharmaceutical analysis

Fluroquinolone antibiotics (FQA) are a class of important synthetic antibacterial agents, which are active against Gram positive and Gram negative bacteria. ${ }^{2)}$ They are receiving a significant attention due to their broad spectrum of activity, potency, variable indications and excellent pharmacokinetic profiles. Because of their therapeutic importance, numerous analytical methods have been developed for their determinations in pharmaceutical formulations and/or biological fluids; comprehensive reviews for these methods were presented by Carlucci G. ${ }^{3)}$ and Belal F. et al. ${ }^{4)}$ Spectrophotometry, because of its inherent simplicity, low cost, and wide availability in most quality control laboratories comprises the most widely used technique for determination of FQA in bulk and pharmaceutical dosage forms. ${ }^{5-15)}$

$N$-Haloimides have been used as effective analytical reagents for the spectrophotometric determination of many pharmaceutical compounds via oxidation or bromination of these compounds. ${ }^{16-22)} \mathrm{N}$-Bromosuccinimide (NBS), being the most versatile one, is the most commonly used. ${ }^{17-22)}$ The use of NBS as an analytical reagent offered adequate sensitivity and accuracy, in addition to the simplicity and low cost of the analytical method. The use of NBS for the determination of FQA has not been reported yet. Therefore, the present study was undertaken to evaluate NBS as an analytical reagent for the spectrophotometric determination of FQA. The analytical procedure involved the treatment of the FQA with NBS and subsequent measurement of the excess NBS by its reaction with $p$-phenylenediamine (PDA) to give a violet colored product that was measured at $530 \mathrm{~nm}$.

\footnotetext{
Experimental

Equipment An UV-1601 PC (Shimadzu, Japan), and a Lambda-3B (Perkin-Elmer Corporation, Norwalk, U.SA.) ultraviolet-visible spectrophotometers with matched $1-\mathrm{cm}$ quartz cells were used for all measurements.
}

Other equipment used included an electrothermal melting point apparatus (Stuart Scientific Co., Florida, U.S.A.), an infrared spectrometer (IR 20091527, Shimadzu, Kyoto, Japan), and a ${ }^{1} \mathrm{H}-\mathrm{NMR}$ spectrometer (EM-360, $60 \mathrm{MHz}$, Varian Instrument Division, Palo, Alto, CA, U.S.A.).

Chemicals and Materials The following authentic standards were used after confirming their purity and compliance with the pharmaceutical requirements. Amifloxacin (Sterling Winthrop Inc., U.S.A.), ciprofloxacin $\mathrm{HCl}$ (Miles Inc. Pharmaceutical Division, West Haven, Germany), difloxacin $\mathrm{HCl}$ (Abbott Laboratories, North Chicago, U.S.A.), enrofloxacin (Merck, Darmstadt, Germany), gatifloxacin (Bristol-Myers Squibb S.A.E., Cairo, Egypt), levofloxacin (Aventis Pharma S.A.E, Cairo, Egypt), lomefloxacin HC (Searle, Illinois, U.S.A.), norfloxacin $\mathrm{HCl}$ (Egyptian International Pharmaceutical Industries Co., Cairo, Egypt), ofloxacin (Daiichi, Tokyo, Japan), pefloxacin methanesulphonate (Rhone-Poulenc Rorer, Neuilly/Seine, France), and sparfloxacin (Global Napi Pharmaceuticals, Cairo, Egypt). N-Bromosuccinimide (NBS; Aldrich Co., Ltd., Gillingham-Dorst, Germany) was $0.5 \mathrm{mg} / \mathrm{ml}$ aqueous solution. Hydrochloric acid was obtained from El-Nasr Pharmaceutical Chemicals Co. (Cairo, Egypt). p-Phenylenediamine (PDA; Loba Chemie PVT. Ltd., Mumbai, India) was used at a concentration of $0.1 \mathrm{mg} / \mathrm{ml}$ in $0.01 \mathrm{M} \mathrm{HCl}$ solution. DC Alufolien, Kiesselgel 60 F254 precoated TLC plates were purchased from E. Merck (Darmastadt, Germany) All other chemicals and solvents used throughout this study were of analytical grade.

Pharmaceutical Dosage Forms The following pharmaceutical formulations were obtained from the local markets and analyzed. Ciprofloxacin ${ }^{\mathbb{B}}$ tablets (Amriya Pharmaceutical Industries, Alexandria, Egypt) are labeled to contain $500 \mathrm{mg}$ of ciprofloxacin $\mathrm{HCl}$ per tablet. Ciprofloxacin ${ }^{\circledR}$ intravenous infusion (Amriya Pharmaceutical Industries, Alexandria, Egypt) is labeled to contain $200 \mathrm{mg}$ of ciprofloxacin lactate per $100 \mathrm{ml}$ infusion. Cipro ${ }^{\mathbb{R}}$ optic drops (Chemical Industries Development Co., Giza, Egypt) are labeled to contain $3.5 \mathrm{mg}$ of ciprofloxacin $\mathrm{HCl}$ per $1 \mathrm{ml}$ solution. Lomoxin ${ }^{\circledR}$ tablets (Minapharm Egypt for Egyptian Group for Drug Trading, 10th Ramadan City, Egypt) are labeled to contain $400 \mathrm{mg}$ of lomefloxacin per tablet. Orchacin $^{\circledR}$ eye drops (Minapharm Egypt for Egyptian Group for Drug Trading, 10th Ramadan City, Egypt) are labeled to contain $3 \mathrm{mg}$ of lomefloxacin per $1 \mathrm{ml}$ solution. Neofloxin ${ }^{\circledR}$ tablets (Alexandria Co., for Pharmaceuticals, Alexandria, Egypt) are labeled to contain $400 \mathrm{mg}$ of norfloxacin per tablet. Conaz $^{\circledR}$ tablets (Pharaonia Pharmaceuticals for Wockhardt Egypt, Alexandria, Egypt) are labeled to contain $400 \mathrm{mg}$ of norfloxacin and $600 \mathrm{mg}$ of tinidazole per tablet. Ofloxacin ${ }^{\mathbb{R}}$ tablets (Sedico Pharmaceutical Co., 6th Oc- 
Table 1. Chemical Structures of the Investigated Fluoroquinolone Antibiotics<smiles>[R9]c1c(F)c([R9])c2c(=O)c(C(=O)O)cn([R8])c2c1[R]</smiles>

\begin{tabular}{|c|c|c|c|c|}
\hline Fluoroquinolone & $\mathrm{R}_{1}$ & $\mathrm{R}_{2}$ & $\mathrm{R}_{3}$ & $\mathrm{R}_{4}$ \\
\hline Amifloxacin & $-\mathrm{NCHCH}_{3}$ & $\mathrm{H}$ & & $\mathrm{H}$ \\
\hline Ciprofloxacin & $\rightarrow$ & $\mathrm{H}$ & & $\mathrm{H}$ \\
\hline Difloxacin & & $\mathrm{H}$ & & $\mathrm{H}$ \\
\hline Enrofloxacin & $\rightarrow$ & $\mathrm{H}$ & & $\mathrm{H}$ \\
\hline Gatifloxacin & $\rightarrow$ & $\mathrm{H}$ & & $-\mathrm{OCH}_{3}$ \\
\hline Levofloxacin & $\begin{array}{l}-\mathrm{CHCH}_{2}- \\
\mathrm{L}^{-} \\
\mathrm{CH}_{3}\end{array}$ & $\mathrm{H}$ & & $-\mathrm{OH}$ \\
\hline Lomefloxacin & $\mathrm{CH}_{3}-\mathrm{CH}_{2}-$ & $\mathrm{H}$ & & $\mathrm{F}$ \\
\hline Norfloxacin & $\mathrm{CH}_{3}-\mathrm{CH}_{2}-$ & $\mathrm{H}$ & & $\mathrm{H}$ \\
\hline Ofloxacin & $\begin{array}{l}-\mathrm{C}_{\mathrm{CH}_{3}} \\
\mathrm{HCH}_{2}-\end{array}$ & $\mathrm{H}$ & & $-\mathrm{OH}$ \\
\hline Pefloxacin & $\mathrm{CH}_{3}-\mathrm{CH}_{2}-$ & $\mathrm{H}$ & & $\mathrm{H}$ \\
\hline Sparfloxacin & $\rightarrow$ & $-\mathrm{NH}_{2}$ & & $\mathrm{~F}$ \\
\hline
\end{tabular}

tober city, Egypt) are labeled to contain $200 \mathrm{mg}$ of ofloxacin per tablet. Ofloxacin $^{\circledR}$ eye drops (Kahira Pharma \& Chem. Indust. Co., Cairo, Egypt) are labeled to contain $3 \mathrm{mg}$ of ofloxacin per $1 \mathrm{ml}$ solution. Globacin ${ }^{\circledR}$ tablets (Global Napi Pharmaceuticals, Cairo, Egypt) are labeled to contain $400 \mathrm{mg}$ of pefloxacin mesylate dihydrate per tablet. Peflacin ${ }^{\circledR}$ ampoules (RhonePoulenc Rorer Laboratoire Roger Bellon, Neuilly/Seine, France) are labeled to contain $400 \mathrm{mg}$ of pefloxacin mesylate dihydrate per ampoule. Sparcin ${ }^{\circledR}$ tablets (Global Napi Pharmaceuticals, Cairo, Egypt) are labeled to contain $200 \mathrm{mg}$ of sparfloxacin per tablet.

Preparation of Standard and Sample Solutions Preparation of Stock Standard Solution: Into a $50-\mathrm{ml}$ calibrated flask, $100 \mathrm{mg}$ of the drug was accurately weighed and dissolved in about $40 \mathrm{ml}$ of $0.01 \mathrm{~N} \mathrm{HCl}$. For complete dissolution of norfloxacin, lomefloxacin, enrofloxacin, amifloxacin, gatifloxacin, and sparfloxacin, the contents of the flask was sonicated for $5 \mathrm{~min}$. The resulting solutions were completed to volume with $0.01 \mathrm{~N} \mathrm{HCl}$. These stock solutions $(2 \mathrm{mg} / \mathrm{ml})$ were diluted with $0.01 \mathrm{~N} \mathrm{HCl}$ to obtain the suitable concentrations that lie in the linear range of the assay method for each particular drug.

Preparation of Tablets Sample Solutions: Twenty tablets were weighed and finely powdered. A quantity of the powdered tablets equivalent to the content of one tablet was transferred into a $100-\mathrm{ml}$ calibrated flask, dissolved in $80 \mathrm{ml} 0.01 \mathrm{~N}$ hydrochloric acid, swirled and sonicated for $10 \mathrm{~min}$. The contents were diluted to volume with the corresponding solvent (as in stock solutions), shaken well for $15 \mathrm{~min}$, and filtered. The first portion of the filtrate was rejected, and a measured volume of the filtrate was diluted quantitatively with $0.01 \mathrm{~N} \mathrm{HCl}$ to yield suitable concentrations that were in the linear range of each particular drug.

General Analytical Procedure One milliliter of the standard or sample solution was transferred into a $10-\mathrm{ml}$ calibrated flask. One milliliter of NBS reagent solution $(0.5 \mathrm{mg} / \mathrm{ml})$ was added and mixed. The reaction was allowed to proceed for $15 \mathrm{~min}$ at room temperature $\left(25 \pm 5^{\circ} \mathrm{C}\right)$. One milliliter of PDA reagent solution $(0.1 \mathrm{mg} / \mathrm{ml})$ was added and mixed. The reaction was allowed to proceed for $5 \mathrm{~min}$ at room temperature $\left(25 \pm 5^{\circ} \mathrm{C}\right)$. The volume was then completed to the mark with distilled water. The decrease in the absorbance $(\Delta A)$ of the solution was measured at $530 \mathrm{~nm}$ against reagent blanks treated in a similar manner. The positions of the cuvettes of the samples and the blanks were exchanged for direct measurement of the decrease in the absorbance.

Determination of Molar Ratios of the Reactions Reaction of NBS with FQA: The Job method of continuous variation was used. ${ }^{23)}$ Master equimolar solutions $\left(1 \times 10^{-3} \mathrm{M}\right)$ of the investigated drugs and NBS reagent were prepared. Series of $10-\mathrm{ml}$ portions of the master solutions of drugs and reagent were prepared comprising different complementary proportions $(0: 10,1: 9, \ldots, 9: 1,10: 0$, inclusive $)$ in 25 -ml calibrated flasks. The reactions were allowed to proceed for $15 \mathrm{~min}$ at room temperature $\left(25 \pm 5^{\circ} \mathrm{C}\right)$, and then $1 \mathrm{ml}$ of PDA reagent $(0.1 \mathrm{mg} / \mathrm{ml})$ was added. The flasks were allowed to stand for $5 \mathrm{~min}$, and then completed to the mark with water. The decrease in the absorbance $(\Delta A)$ values of the resulting solutions was measured at $530 \mathrm{~nm}$.

Reaction of NBS with PDA: One-milliliter aliquots of NBS solution $\left(5.4 \times 10^{-3} \mathrm{M}\right)$ were transferred into $25-\mathrm{ml}$ calibrated flasks. To each flask, 1 to $10 \mathrm{ml}$ aliquots of PDA solution $\left(5.4 \times 10^{-3} \mathrm{M}\right)$ were added, and the reactions were allowed to proceed for $5 \mathrm{~min}$ at room temperature $\left(25 \pm 5^{\circ} \mathrm{C}\right)$. The reaction mixtures were completed to volume with water, and the absorbance was measured at $530 \mathrm{~nm}$ against reagent blanks prepared without NBS.

Preparation of the Reaction Product between NBS and Norfloxacin Into a $25-\mathrm{ml}$ round-bottom flask a solution, glacial acetic acid solutions of NBS $(0.89 \mathrm{~g}, 2 \mathrm{mmol})$ and norfloxacin $(0.80 \mathrm{~g}, 1 \mathrm{mmol})$ were transferred and 
mixed. The reaction was monitored by TLC until it gave a single spot different from that of the norfloxacin spot; the reaction proceeded for $30 \mathrm{~min}$. The formed yellowish white precipitate that formed was filtered, washed 3 times with diethyl ether and then dried over anhydrous sodium sulphate. The dried material (mp $275^{\circ} \mathrm{C}$ ) was analyzed by UV-vis., IR, and ${ }^{1} \mathrm{H}-\mathrm{NMR}$ spectrometry for its structure elucidation.

\section{Results and Discussion}

Reactions Involved and Absorption Spectra The analytical reaction involved two steps; the first one was concerned with the treatment of the investigated FQA with a known excess amount of NBS. The second step involved the determination of the excess unreacted NBS via its reaction with PDA reagent. The reaction of the investigated FQA with NBS was monitored by measuring the excess unreacted NBS at different time intervals via formation of a chromogenic product with PDA. The addition of PDA solution to the NBS solution resulted in the formation of a violet colored product that showed $\lambda_{\max }$ at $530 \mathrm{~nm}$, whereas the FQA, NBS, and PDA had no absorption capability above $360 \mathrm{~nm}$ (Fig. 1). The decrease in the absorption intensity $(\Delta A)$ at $530 \mathrm{~nm}$, caused by the presence of the FQA, was directly proportional to the amount of the drug in its original sample.

Optimization of Reaction Variables Concentration of NBS and PDA: According to the above-mentioned reaction, NBS solution should be added in excess to react with the FQA. By measuring the excess NBS reagent, the consumed reagent would correspond to the amount of the drug. The highest concentration of NBS reagent that reacts with a definite concentration of PDA reagent (in absence of FQA) and gives the highest absorption value within the practical sensitivity range of absorption values ( $c a .0 .9)$ was considered as optimum. The effect of NBS reagent concentration was studied by carrying out the reaction using $1 \mathrm{ml}$ of different concentrations in the range of $0.05-1 \mathrm{mg} / \mathrm{ml}$. In this study, $1 \mathrm{ml}$ of PDA reagent $(0.1 \mathrm{mg} / \mathrm{ml})$ was used for color development. The results revealed that the $\Delta A$ values increased by increasing the concentration of NBS until the maximum $\Delta A$ value was obtained at a concentration of $0.4-0.5 \mathrm{mg} / \mathrm{ml}$, and further increase in the concentration of the reagent had a slight negative effect on the $\Delta A$ values (Fig. 2). A concentration of $0.5 \mathrm{mg} / \mathrm{ml}$ was selected for the subsequent experiments. Using this concentration, similar series of experiments were performed to establish the optimum concentration of PDA reagent. The results revealed that the optimum concentration of PDA was $0.1 \mathrm{mg} / \mathrm{ml}$ (Fig. 2).

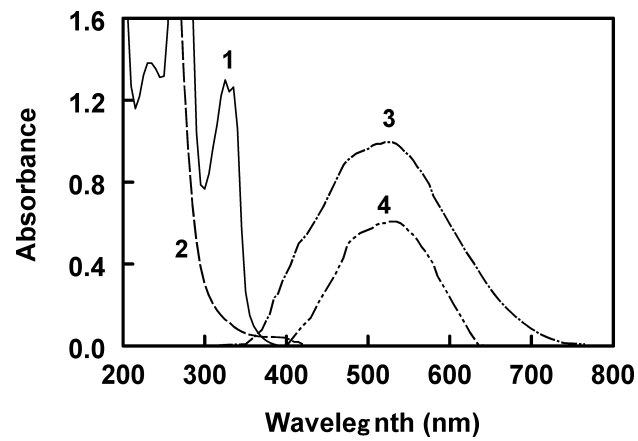

Fig. 1. Absorption Spectra of Norfloxacin (1), NBS (2), and Reaction Product of NBS with PDA in Absence and Presence of $8 \mu \mathrm{g} / \mathrm{ml}$ of Norfloxacin (3 and 4) Respectively
Reaction Time and Temperature: Under these conditions, the reaction between the investigated drugs and NBS was completed within $10 \mathrm{~min}$ at room temperature $\left(25 \pm 5^{\circ} \mathrm{C}\right)$, and the $\Delta A$ values remained unaffected up to $20 \mathrm{~min}$, however, a longer reaction time had a negative effect (Fig. 3). For more precise readings the reaction was allowed to proceed for $15 \mathrm{~min}$. Although Fig. 3 illustrates the effect of time on the reaction of NBS with lomefloxacin, norfloxacin, and sparfloxacin, as representative examples, however similar results were obtained with the other investigated FQA. After addition of PDA reagent, complete color development was achieved within $5 \mathrm{~min}$. Elevated temperatures had no significant accelerating effect on the reaction.

Diluting Solvent and Stability of the Chromogen: Dilution of the reaction mixture with different solvents showed that the position of $\lambda_{\max }$ and the absorption intensities were affected. The highest readings were obtained when water was used as a diluting solvent. Substitution of water with other solvents (ethanol, acetone, propan-1-ol, propan-2-ol, butan1-ol, and 1,4-dioxane) resulted in slight bathochromic shifts, and the absorption intensities were depressed. The absorbance values $(A)$ were correlated with the dielectric constants (DEC) of the solvents used for dilution. ${ }^{24,25)}$ The correlation equation was: $A=0.7836+0.0029 \mathrm{DEC}\left(r^{2}=0.8241\right)$. After dilution with water, the absorbance values were found to be stable for at least $30 \mathrm{~min}$.

Molar Ratio and Reaction Mechanisms Reaction of FQA with NBS: Examination of the stoichiometry for the

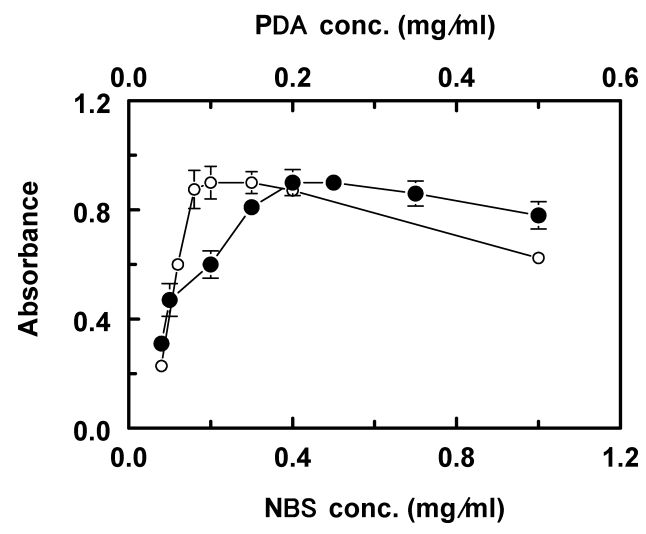

Fig. 2. Effect of Concentration of NBS $(-)$ and PDA $(O)$ on the Absorption Intensity of Their Reaction Product in the Absence of FQA

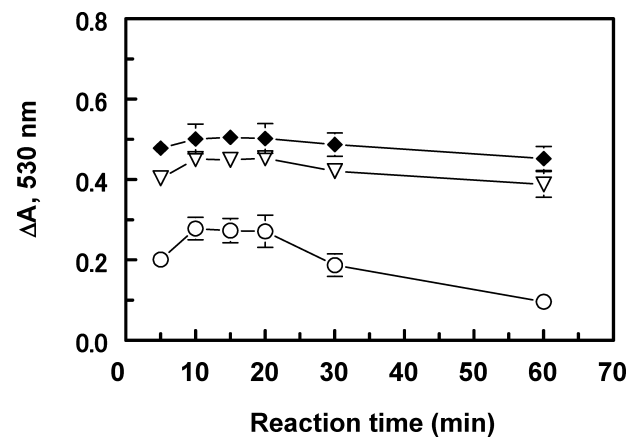

Fig. 3. Effect of Time on the Reaction of NBS with Norfloxacin (O), Levofloxacin, $(\nabla)$, and Sparfloxacin $(\diamond)$

The concentrations of the drugs were 5,10 , and $12 \mu \mathrm{g} / \mathrm{ml}$ for norfloxacin, levofloxacin, and sparfloxacin, respectively. 
(A)
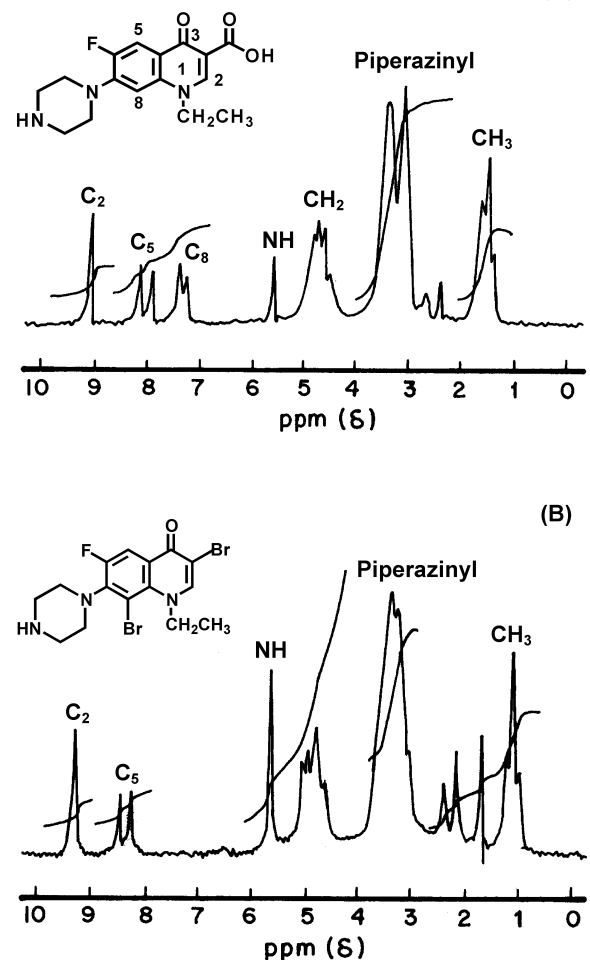

Fig. 4. ${ }^{1} \mathrm{H}-\mathrm{NMR}$ Spectra of Norfloxacin (A) and Its Isolated Reaction Product with NBS (B)

reaction between FQA and NBS revealed that FQA: NBS ratio was $1: 1$ ( $1 \mathrm{~mol}$ of FQA reacts with $1 \mathrm{~mol}$ of NBS) in the cases of gatifloxacin, levofloxacin, lomefloxacin and sparfloxacin, and the ratio was 1:2 (1 mol of FQA reacts with 2 mol of NBS) in the cases of amifloxacin, ciprofloxacin, difloxacin, enrofloxacin, norfloxacin, and pefloxacin.

In order to propose a possible reaction pathway, the product of the reaction between NBS and norfloxacin, as a representative example for FQA, was isolated and examined by different techniques. The product was a yellowish material with a mp of $275^{\circ} \mathrm{C}$. The product had a maximum UV absorption peak $\left(\lambda_{\max }\right)$ at $383 \mathrm{~nm}$; norfloxacin itself showed $\lambda_{\max }$ at $325 \mathrm{~nm}$. The absorption spectrum of the isolated product was the same as that of the reaction mixture between NBS and norfloxacin. The IR spectrum (obtained in $\mathrm{KBr}$ disc) of the product showed the disappearance of the carboxylic acid $\mathrm{C}=\mathrm{O}$ stretch of norfloxacin at $1725-1700$ $\mathrm{cm}^{-1}$, and also the carboxylic hydroxyl group at 3600$3250 \mathrm{~cm}^{-1}$. However, the IR spectra of both norfloxacin and its reaction product with NBS showed the pyridone $\mathrm{C}=\mathrm{O}$ stretch at $1628 \mathrm{~cm}^{-1}$. These data indicated the decarboxylation of norfloxacin. This assumption was supported by the failure of the isolated reaction product to give a positive comlexation reaction with $\mathrm{FeCl}_{3}$ solution, rather than norfloxacin, which gave a red colored complex. ${ }^{26)}$

The ${ }^{1} \mathrm{H}-\mathrm{NMR}$ spectrum (DMSO- $d_{6}$ ) of the product showed the absence of a doublet signal that should appear if a proton at $\mathrm{C}_{3}$ is present, and also the disappearance of the carboxylic group proton that appears offset (Fig. 4). Based on this observation, decarboxylation with substitution for the $\mathrm{C}_{3}$ proton with bromine was suggested. This suggestion was also evidenced by the appearance $\mathrm{C}_{2}$ of the proton as a singlet, rather
A. Reaction of NBS with norfloxacin

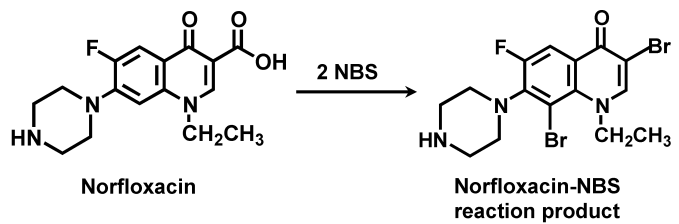

B. Reaction of NBS with PDA

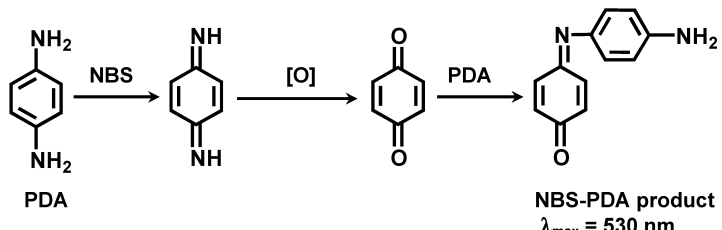

$\lambda_{\max }=\mathbf{5 3 0} \mathrm{nm}$

Fig. 5. Proposed Pathways for the Reactions of NBS with Norfloxacin (A) and PDA (B)

than a doublet peak if a proton at $\mathrm{C}_{3}$ is available for coupling. Bromination at $\mathrm{C}_{8}$ was also suggested by the disappearance of the doublet signal of $\mathrm{C}_{8}$ proton (at $7.2 \mathrm{ppm}$ in NMR spectrum of norfloxacin. These data, in conjunction with the norfloxacin: NBS molar ratio $(2: 1)$ confirmed the bromination at both $\mathrm{C}_{2}$ and $\mathrm{C}_{8}$. The proposed pathway for the reaction between norfloxacin and NBS is given in Fig. 5A. These results were coincident with the reported ability of NBS to accomplish substitution of the bromine for the hydrogen in reactive aromatic compounds in positions $\alpha$ to double bonds and aromatic rings, and also in positions $\alpha$ to the carbonyl groups. ${ }^{27)}$

Reaction of NBS with PDA: The molar ratio of the reaction between NBS and PDA, that gives the colored product, was found to be $1: 2$. This indicated that $1 \mathrm{~mol}$ of NBS reacted with 2 mol of PDA. Based on this finding, the reaction was postulated to proceed according to the pathway given in Fig. 5B. One molecule of PDA was oxidized with NBS to give $p$-benzoquinonediimine, which was further oxidized to produce $p$-benzoquinone. ${ }^{28)}$ The produced $p$-benzoquinone was further condensed with a second molecule of PDA to give the conjugated violet product.

Development and Validation of the Analytical Method Linearity, Limits of Detection and Quantitation: Under the above-mentioned optimum conditions, the calibration graphs correlating the decrease in the absorption intensity $(\Delta A)$ with the corresponding concentration of the drug were constructed. Regression analysis for the results was as carried out using the least-square method. In all cases, Beer's law plots $(n=5)$ were linear with very small intercepts $(-0.020$ $0.0302)$ and good correlation coefficients $(0.9982-0.9998)$ in the general concentration ranges of $3-25 \mu \mathrm{g} / \mathrm{ml}$ (Table 2). The limits of detection (LOD) and limits of quantitation (LOQ) were determined ${ }^{29}$ ) using the formula: LOD or $\mathrm{LOQ}=\kappa \mathrm{SD}_{\mathrm{a}} / b$, where $\kappa=3$ for LOD and 10 for LOQ, $\mathrm{SD}_{\mathrm{a}}$ is the standard deviation of the intercept, and $b$ is the slope. The LOD and LOQ values ranged from $0.33-1.29$ and $1.12-4.31 \mu \mathrm{g} / \mathrm{ml}$, respectively.

Investigations were carried out to correlate the chemical structure with the analytical parameters. The obtained $\log \varepsilon$ values were correlated, using regression analysis, with some physicochemical parameters of the investigated compounds: $\mathrm{p} K_{\mathrm{a}}, \operatorname{clog} \mathrm{P}$, Van der Waal forces (VDW), heat of formation 
Table 2. Quantitative Parameters and Statistical Data for the Studied FQA Analyzed by Reaction with NBS

\begin{tabular}{|c|c|c|c|c|c|c|c|}
\hline Fluoroquinolone & Range $(\mu \mathrm{g} / \mathrm{ml})$ & Intercept $(a)$ & Slope $(b)$ & $\begin{array}{l}\text { Correlation } \\
\text { coefficient }(r)\end{array}$ & $\begin{array}{c}\text { Molar } \\
\text { absorptivity }(\varepsilon) \\
(1 / \mathrm{mol} / \mathrm{cm})\end{array}$ & $\begin{array}{c}\text { LOD } \\
(\mu \mathrm{g} / \mathrm{ml})\end{array}$ & $\begin{array}{c}\text { LOQ } \\
(\mu \mathrm{g} / \mathrm{ml})\end{array}$ \\
\hline Amifloxacin & $5-15$ & 0.0077 & 0.0581 & 0.9993 & 20395 & 0.76 & 2.52 \\
\hline Ciprofloxacin $\mathrm{HCl}$ & $10-25$ & -0.0064 & 0.0337 & 0.9998 & 11183 & 0.45 & 1.52 \\
\hline Difloxacin $\mathrm{HCl}$ & $5-20$ & 0.0007 & 0.0466 & 0.9998 & 19752 & 0.41 & 1.38 \\
\hline Enrofloxacin & $5-20$ & 0.0022 & 0.0388 & 0.9988 & 14325 & 1.13 & 3.75 \\
\hline Gatifloxacin & $3-10$ & 0.0085 & 0.0889 & 0.9993 & 34911 & 0.39 & 1.30 \\
\hline Levofloxacin & $5-20$ & 0.0080 & 0.0449 & 0.9994 & 16954 & 0.65 & 2.15 \\
\hline Lomefloxacin $\mathrm{HCl}$ & $5-15$ & 0.0109 & 0.0482 & 0.9991 & 19265 & 0.90 & 3.00 \\
\hline Norfloxacin $\mathrm{HCl}$ & $5-15$ & -0.0198 & 0.0564 & 0.9994 & 17439 & 0.74 & 2.46 \\
\hline Ofloxacin & $5-20$ & 0.0015 & 0.0426 & 0.9993 & 15509 & 0.67 & 2.22 \\
\hline Pefloxacin & $5-15$ & 0.0302 & 0.0502 & 0.9982 & 23388 & 1.29 & 4.31 \\
\hline Sparfloxacin & $5-20$ & 0.0013 & 0.0414 & 0.9998 & 16513 & 0.34 & 1.12 \\
\hline
\end{tabular}

(HF) and $-\log \mathrm{HF}(\mathrm{pHF})$. The values of parameters other than $\mathrm{p} K$ values were calculated using Chemdraw ultra 2004 software (Cambridgesoft ${ }^{\circledR}$ Corporation, Cambridge, U.S.A.), and the following equations were obtained:

$$
\begin{aligned}
& \log \varepsilon=24.16-4.12 \mathrm{p} K_{\mathrm{a}} \quad(r=-0.650) \\
& \log \varepsilon=7.61-2.08 \mathrm{clog} \mathrm{P} \quad(r=-0.515) \\
& \log \varepsilon=-6.81+5.97 \mathrm{VDW} \quad(r=0.708) \\
& \log \varepsilon=309.34-210.89 \mathrm{HF} \quad(r=-0.621) \\
& \log \varepsilon=1.72+0.25 \mathrm{pHF} \quad(r=0.648)
\end{aligned}
$$

It was observed that the sensitivity of the method, in terms of $\log \varepsilon$ value, was positively correlated with the Van der Waal forces and $\mathrm{pHF}$, while good negative correlations were found with the $\mathrm{p} K_{\mathrm{a}}$ values and HF.

Precision: The precision of the proposed method was determined by analyzing 6 replicate samples of standard FQA solutions at one concentration level for each drug. The assays gave satisfactory results; the relative standard deviations (RSD) were less than $2 \%$. This level of precision of the proposed methods was adequate for the quality control analysis of the investigated FQA in the pharmaceutical dosage forms.

Interference Liabilities: Before proceeding with the analysis of the investigated drugs in their pharmaceutical dosage forms, interference liabilities were carried out to explore the effect of common excipients that might be added during formulations. Samples were prepared by mixing known amount $(30 \mathrm{mg})$ of the drug with various amounts of the common excipients: lactose, sucrose, starch, magnesium stearate, and ascorbic acid sodium salt (co-formulated with pefloxacin as stabilizer in the ampoule form). The analysis of these laboratory-prepared samples were carried out using the general recommended procedure, and the recovery values were determined. No interference was found from lactose, sucrose, starch, and magnesium stearate; the recovery values were $98.8-100.8 \pm 0.24-1.43 \%$. This indicated the absence of interference from these excipients. On the other hand, ascorbic acid was found to interfere with the assay procedure (the recovery value was $105.9 \pm 0.85 \%$ ). This interference was attributed to the liability of ascorbic acid to the oxidation with NBS. ${ }^{30)}$ This interference could be eliminated by adding $1 \mathrm{ml}$ of $0.1 \%(\mathrm{w} / \mathrm{v})$ aqueous solution of potassium bromate to the pefloxacin-containing ampoule samples prior to their analysis; the recovery was reduced to $101.3 \pm 0.74 \%$. The selection of potassium bromate for this purpose was based on its mild oxidizing power $\left(\mathrm{E}_{\mathrm{BrO}_{3} / \mathrm{Br}}^{0}=+0.76 \mathrm{~V}\right)$ that can oxidize ascorbic acid without affecting the drug. Tinidazole which was co-formulated with norfloxacin in $\mathrm{CONAZ}^{\circledR}$ tablets did not show any interference. In addition, the proposed method has the advantage that the analysis is performed at $530 \mathrm{~nm}$ of the visible region away from the UV-absorbing capabilities of interferents that might be co-extracted from dosage forms.

Robustness and Ruggedness: Robustness was examined by evaluating the influence of small variation of method variables (concentration of the analytical reagents, and reaction time) on the performance of the proposed method. In these experiments, one parameter was changed where as the others were kept unchanged, and the recovery percentage was calculated each time. It was found that none of these variables significantly affect the method; the recovery values were $98.1-$ $100.6 \pm 0.19-0.98 \%$. This provided an indication for the reliability of the proposed method during its routine application for analysis of the investigated drugs.

Ruggedness was tested by applying the proposed method to the assay of the same samples of the investigated drugs using the same operational conditions but using two different instruments at two different laboratories and at different elapsed times. Results obtained from instrument-to-instrument and day-to-day variations were found to be reproducible, as the RSD did not exceed $2 \%$.

Application of the Proposed Method to Analysis of Dosage Forms It is evident from the aforementioned results that the proposed method gave satisfactory results with the investigated drugs in bulk. Thus their pharmaceutical dosage forms were subjected to the analysis for their contents of the active ingredient by the proposed method and the official method. The label claim, as percentages, ranged from $99.4-100.5 \pm 0.16-0.63 \%$ (Table 3 ). These results were compared with those obtained from the official ${ }^{31)}$ or the reported $^{32,33)}$ methods by statistical analysis with respect to the accuracy ( $t$-test) and precision ( $F$-test). No significant differences were found between the calculated and theoretical values of $t$ - and $F$-tests at the $95 \%$ confidence level proving similar accuracy and precision in the analysis of the investigated drugs in their dosage forms.

\section{Conclusions}

The results demonstrated the usefulness of the NBS-PDA system in the spectrophotometric analysis of fluoroquinolone 
Table 3. Analysis of FQA in Their Pharmaceutical Formulations by the Proposed and Pharmacopoeial or Reported Methods

\begin{tabular}{|c|c|c|c|c|}
\hline \multirow{2}{*}{ Dosage form } & \multicolumn{2}{|c|}{ Label claim $(\% \pm \text { S.D. })^{a)}$} & \multirow{2}{*}{$t$-value ${ }^{b)}$} & \multirow{2}{*}{$F$-value $^{b}$} \\
\hline & Proposed & Reference $^{c)}$ & & \\
\hline Neofloxacin tablets & $99.5 \pm 0.29$ & $99.7 \pm 0.22$ & 1.27 & 2.69 \\
\hline Conaz tablets & $99.7 \pm 0.16$ & $100.0 \pm 0.79$ & 1.14 & 2.02 \\
\hline Ciprofloxacin tablets & $99.5 \pm 0.30$ & $99.4 \pm 0.34$ & 0.77 & 1.27 \\
\hline Ciprofloxacin infusion & $100.2 \pm 0.23$ & $100.1 \pm 0.43$ & 0.52 & 3.36 \\
\hline Cipro otic drops & $100.3 \pm 0.24$ & $100.4 \pm 0.34$ & 1.06 & 1.99 \\
\hline Ofloxacin tablets & $100.5 \pm 0.19$ & $100.6 \pm 0.38$ & 0.46 & 4.13 \\
\hline Ofloxacin eye drops & $100.0 \pm 0.29$ & $99.8 \pm 0.64$ & 0.66 & 4.81 \\
\hline Lomoxin tablets & $100.5 \pm 0.19$ & $100.8 \pm 0.41$ & 0.21 & 3.94 \\
\hline Orchacin eye drops & $100.3 \pm 0.63$ & $99.6 \pm 0.90$ & 1.27 & 2.05 \\
\hline Sparcin tablets & $99.4 \pm 0.45$ & $99.3 \pm 0.16$ & 0.46 & 1.49 \\
\hline Globacin tablets & $99.5 \pm 0.40$ & $99.0 \pm 0.57$ & 1.85 & 2.01 \\
\hline Peflacin ampoules & $99.4 \pm 0.32$ & $99.7 \pm 0.24$ & 1.65 & 1.76 \\
\hline
\end{tabular}

a) Values are mean of 5 determinations \pm S.D. b) The tabulated values of $t$ - and $F$ - at $95 \%$ confidence limit are 2.78 and 6.39 , respectively. c) refs. $29-31$.

antibiotics. The proposed method is characterized by its high sensitivity, which permits the determination of a concentration down to $0.33 \mu \mathrm{g} / \mathrm{ml}$, procedural simplicity of the procedures, and reliability of the results. Furthermore, the analytical reagents are inexpensive, have excellent shelf life, and are available in any analytical laboratory. The proposed method can be applied in quality control laboratories for the routine analysis of the investigated drugs in raw materials, in pharmaceutical formulations.

\section{References and Notes}

1) Present address: Department of Pharmaceutical Chemistry, College of Pharmacy, King Saud University; P.O. Box 2457, Riyadh 11451, Saudi Arabia.

2) Martindale, "The Complete Drug Reference," 31th ed., ed. by Sweetman S. C., Royal Pharmaceutical Society, London, 1996, pp. 207210, 260-261.

3) Carlucci G., J. Chromatogr. A, 812, 343-367 (1998).

4) Belal F., Al-Majed A. A., Al-Obaid A. M., Talanta, 50, 765-786 (1999).

5) Salem H., Am. J. Appl. Sci., 2, 719-729 (2005).

6) Abd Allah O. M., Assiut Univ. Bull. Pharm. Sci., 27, 215-222 (2004).

7) El-Brashy A. M., Metwally M. E., El-Sepai F. A., IL Farmaco, 59, 809-817 (2004).

8) El-Brashy A. M., Metwally M. E., El-Sepai F. A., Bull. Korean Chem. Soc., 25, 365-372 (2004).

9) Gowda B. G., Seetharamappa J., Anal. Sci., 19, 461-464 (2003).

10) Suslu I., Tamer A., Anal. Lett., 36, 1163-1181 (2003).

11) Mostafa S., El-Sadek M., Awadalla E., J. Pharm. Biomed. Anal., 27, $133-142$ (2002).

12) Nagaralli B. S., Seetharamappa J., Melwanki M. B., J. Pharm. Biomed. Anal., 29, 859-864 (2002).

13) Mostafa S., El-Sadek M. E., Alla A., J. Pharm. Biomed. Anal., 28, $173-180(2002)$
14) Rizk M., Belal F., Ibrahim F., Ahmed S., Sheribah Z. A., J. AOAC Int., 84, 368-375 (2001).

15) Naixing W., Xuezhen R., Zhikun S., Wei J., Chunbo L., Xiaoru L., Talanta, 51, 595-598 (2000).

16) Saleh G., Analyst, 121, 641-645 (1996).

17) Rahman N., Azmi S. N., IL Farmaco, 59, 529-536 (2004).

18) El-Yazbi F. A., Gazy A. A., Mahgoub H., El-Sayed M. A., J. Pharm. Biomed. Anal., 31, 1027-1034 (2003).

19) Amin I. S., Ahmed A. S., Dessouki H. A., Spectrochim. Acta A, Mol. Biomol. Spectrosc., 59, 695-703 (2003).

20) Gowda B. G., Seetharamappa J., Anal. Sci., 18, 671-674 (2002).

21) Wadood H. A., Mohamed H. A., Abdelfattah F. A., Boll. Chim. Farm., 141, 52-56 (2002).

22) Alwarthan A. A., Al-Obaid A. M., J. Pharm. Biomed. Anal., 14, 579582 (1996).

23) Job P., Ann. Chem., 16, 97 (1963), in "Advanced Physicochemical Experiments," 2nd ed., Oliner and Boyd, Edinburgh, 1964, p. 54.

24) "Vogel's Textbook of Practical Organic Chemistry," 5th ed., Longman group U.K. Ltd., England, 1989, pp. 1442-1444.

25) Connors K. A., "A Textbook of Pharmaceutical Analysis," 3rd ed., Wiley Interscience, New York, 1982, p. 206.

26) Bhowal S. K., Das T. K., Anal. Lett., 24, 25 (1991).

27) Patai S., "The Chemistry of Functional Groups, the Chemistry of Halides, Pseudo halides and Azides," Part II, John Wiley \& Sons, New York, p. 1104.

28) Finar I. L., "Organic Chemistry: The Fundamental Principles," 6th ed., Vol. 1, Longman, 1966, p. 724.

29) The United States Pharmacopeia 24, The National Formulary 19, U.S Pharmacopeial Convention Inc., Rockville MD, 2000, pp. 21512152.

30) Roy R. B., Conetta A., J. AOAC Int., 59, 1244-1250 (1976).

31) "The British Pharmacopoeia," H.M. Stationary Office, London, 2003.

32) Askal H. F., Assiut Univ. Bull. Pharm. Sci., 20, 75-85 (1997).

33) Meyyanathan S. N., Sebastian M., Suresh B., Indian Drugs, 35, 344 347 (1998). 